\title{
PERFORMANCE COMPARISON OF DIFFERENT THERMAL FLUIDS IN CONCENTRATING SOLAR PLANTS
}

\author{
Maria Laura Mastellone ${ }^{1}$, Antonio Mariani ${ }^{2}$, Ernesto Misso ${ }^{2}$, Biagio Morrone ${ }^{2 *}$, \\ Andrea Unich ${ }^{2}$, Lucio Zaccariello ${ }^{1}$ \\ ${ }^{1}$ Department of Environmental, Biological and Pharmaceutical Sciences and Technologies DiSTABiF - \\ Università della Campania "Luigi Vanvitelli" - Caserta, 81100 - Italy \\ ${ }^{2}$ Dept. of Engineering DI - Università della Campania "Luigi Vanvitelli” - Aversa, (CE) 81031 - Italy
}

\begin{abstract}
Concentrating Solar Plants (CSP) represent a feasible alternative to fossil fuel driven power plants. Anyway, technical and economic issues severely prevent their large diffusion over the world.

In this paper, a numerical investigation is accomplished to predict the performance of a CSP without thermal storage (TES). A stationary, 1-D model of heat transfer fluid (HTF) is presented, taking into account the heat losses occurring along the Heat Collector Element (HCE). A Southern Italy location is considered for the solar plant simulation, and two HTF thermal oils, Therminol VP1 and Therminol 62, are compared in terms of thermal power delivered to the power plant block. HTF temperature distribution and velocity profile along the solar plant are obtained to evaluate the performance of a coupled Organic Rankine Cycle (ORC) plant, simulated using the DWSIM programme, emphasizing the differences when using three different types of working fluids, i.e. wet, dry and isentropic.
\end{abstract}

KEY WORDS: Concentrating solar plant, thermal fluid, parabolic trough concentrator, ORC fluids.

\section{INTRODUCTION}

The increasing global energy consumption together with the $\mathrm{CO} 2$ emissions increment and the fossil fuel depletion are the major challenges our society is facing nowadays. Solar energy exploitation for electric power production on large scale can partially solve the environmental issues [1].

Concentrating Solar Plants (CSP) represent a feasible alternative to fossil fuel driven power plants. The parabolic trough technology, that represents around $80 \%$ of the total installed solar plants [2], is considered one of the key technologies particularly in countries with high solar irradiation. Anyway, it is well known that technical and economic issues severely prevent the spreading of such plants.

For several years, research activities have been developing new solutions with the aim of either performance improvement and/or cost reduction, especially for the solar Parabolic Trough Collectors (PTCs) [3].

Many investigations have been carried out about the PTC performance developing analytical and numerical methods dealing with thermal and optical models [1,2,4-7]. These models solve non-linear differential equations. Forristall [8] described the development, validation, and use of one-dimensional and twodimensional heat transfer models of PTC.

Notwithstanding the scientific literature dealing with CSP, the coupling of PTC with the Power Block has not received sufficient attention to the authors' knowledge.

This paper is aimed to bridge this gap and a numerical investigation is accomplished to predict the performance of a CSP without thermal storage (TES). CSPs are composed of different subsystems connected each other. The Solar plant is made up of parabolic trough concentrators (PTC) which reflect the sun energy on a receiver tube inside which a heat transfer fluid (HTF) flows. The HTF is heated along the pipes of the Heat Collector Element (HCE) and it transfers heat to the Power block working fluid, an Organic Fluid, because of the low temperatures that can be provided by PTCs are usually not larger than $400{ }^{\circ} \mathrm{C}$.

*Corresponding Author: biagio.morrone@unicampania.it 
In this paper, a stationary, 1-D model of the HTF is presented, for different irradiance values as well as heat losses along the PTC. Choosing a Southern Italy location for the solar plant simulation, two HTF thermal oils, Therminol VP1 and Therminol 62 [9], are compared in terms of thermal power delivered to the power plant block, setting as input HTF temperature and pressure values at solar field inlet section. The investigation of the HTF temperature distribution and velocity profile along the solar plant provides the performance of the coupled ORC plant, simulated using the DWSIM programme, emphasizing the differences using two oils and three different types of working fluids: wet, dry and isentropic fluids.

\section{HEAT TRANSFER MODEL OF PTC RECEIVER SYSTEM}

The investigated system is made of a PTC, a parabolic shaped sheet of highly reflective material and a linear receiver referred to as Heat Collector Element (HCE), whose longitudinal section is reported in Figure 1(a), each section having a length of $4.06 \mathrm{~m}$. It is made of a tube inside which the HTF flows and is coated with paintings to obtain the required optical properties of high absorptivity in the sun spectrum and low emissivity in the infrared far field, as reported in [8] and [10]. The different sections of HCE are collected together using bellows to reduce heat losses. The cross section of the HCE is reported in Figure 1(b), displaying also the thermal power terms which account for the energy balance.

Steady-state regime is investigated both for the ORC and the solar field. For the latter, different irradiance conditions are evaluated, for the chosen location during some periods of the year.

The thermo-fluid model in the HCE is one-dimensional, taking into account the variation of the thermophysical properties as a function of the oil temperature. The mass and energy balance considering an elemental volume are:

$$
\begin{gathered}
\dot{m}=(\rho w)_{i} A_{C}=(\rho w)_{i+1} A_{C} \\
\dot{m}\left(c_{i+1} T_{i+1}-c_{i} T_{i}\right)=q_{N E T} P \Delta x-q_{c o n d} A_{C}
\end{gathered}
$$

with $q_{\mathrm{NET}}$ and $q_{\mathrm{cond}}$ are the net flux entering the flowing oil inside the HCE and the conduction heat transfer along the z-axis, respectively. Since the Peclet number in pipes is large, usually order of magnitude greater than $10^{4}$, the axial heat conduction can be neglected.

The net thermal power entering the oil is given, considering Figure 1(b), by:

$$
Q_{N E T}=I A-Q_{\text {conv }}-Q_{\text {irr }}
$$

where conv and irr represent the heat losses by convection and radiation, respectively. To account for the heat losses in Eq.(3), local temperature of the external wall glass surface is required at each axial location. The evaluation of the heat losses is more involved than that, because the thermal performance of the HCE is affected by the heat balance inside the receiver, considering the thermal and optical performance of the surfaces involved, as reported in Figure 1(b), where the main heat fluxes are displayed.

The solar field is made of 5 strings each of which with a total length of $224 \mathrm{~m}$. The inlet temperature of the HTF in the solar field has been chosen equal to $100^{\circ} \mathrm{C}$. The irradiance data used in the numerical simulations are obtained for the chosen location (Aversa, Italy, 40 $58^{\prime} 23^{\prime \prime} \mathrm{N}$ and $14^{\circ} 12^{\prime} 17^{\prime \prime} \mathrm{E}$ ) from PVGIS database [11].

$$
Q_{i n c}=\frac{I \eta_{\text {opt }} A_{c} L_{\text {mir }}}{\pi D_{\text {ext }}}
$$

The evaluation of the incident power on the HCE is given by Eq.(4), being $I$ the irradiance, $\eta_{\text {opt }}$ the optical efficiency of the reflector, which considers the non-ideality of the sunlight reflection [8] and calculated around $0.8, A_{c}$ the cross section of the steel absorber pipe, $L_{m i r}$ the length of the receiver and $D_{\text {ext }}$ the external diameter of the HCE. 


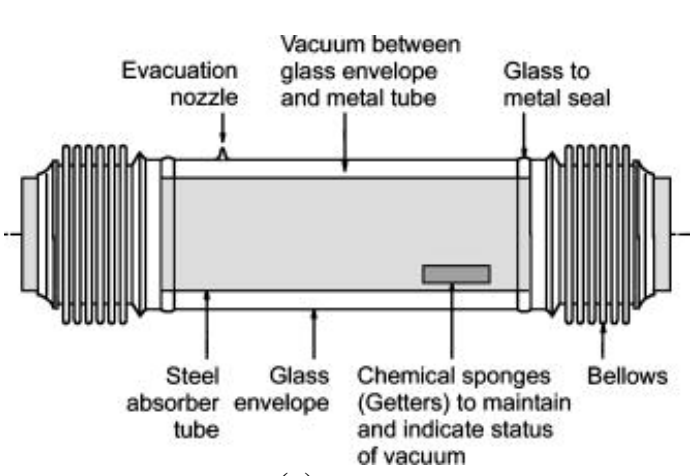

(a)

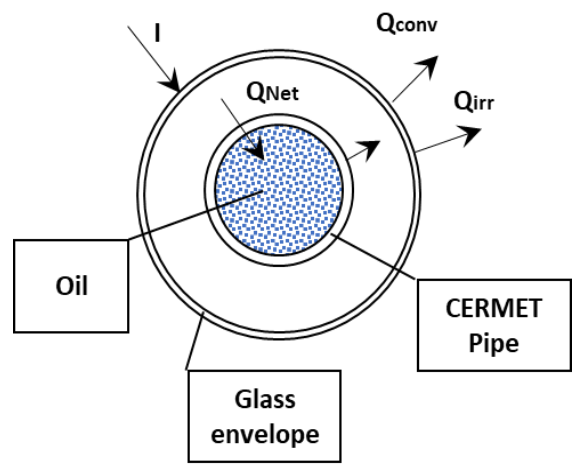

(b)

Fig. 1 (a) Longitudinal sketch view of a HCE tube receiver and (b) its cross-sectional view.

Table 1 displays the most important physical properties of the two investigated oils, showing also the rough estimated cost per $\mathrm{kg}[9]$.

Table1 Main properties of the two investigated oils, Therminol 62 and Therminol VP-1 [9].

\begin{tabular}{c|c|c}
\hline Properties & Therminol 62 & Therminol VP-1 \\
\hline Melting Temperature $\left[{ }^{\circ} \mathrm{C}\right]$ & -23 & 12 \\
Boiling Temperature $\left[{ }^{\circ} \mathrm{C}\right]$ & 333 & 257 \\
Critical pressure $[\mathrm{bar}]$ & 15 & 33.1 \\
Critical Temperature $\left[{ }^{\circ} \mathrm{C}\right]$ & 487 & 499 \\
Molar Mass $[\mathrm{kg} / \mathrm{kmol}]$ & 252 & 166 \\
Rough Estimated Cost $[€ / \mathrm{kg}]$ & 2.0 & 6.0 \\
\hline
\end{tabular}

\section{POWER BLOCK}

The numerical procedure assumes the net electric power of the Power Block equal to 1 MWe. The investigated fluids are: R134a, R245fa and water, the first two belonging to the ORC fluids. These three fluids are chosen because they represent the three typical fluids: isentropic, dry and wet. Their behaviour is different during expansion in steam turbines.

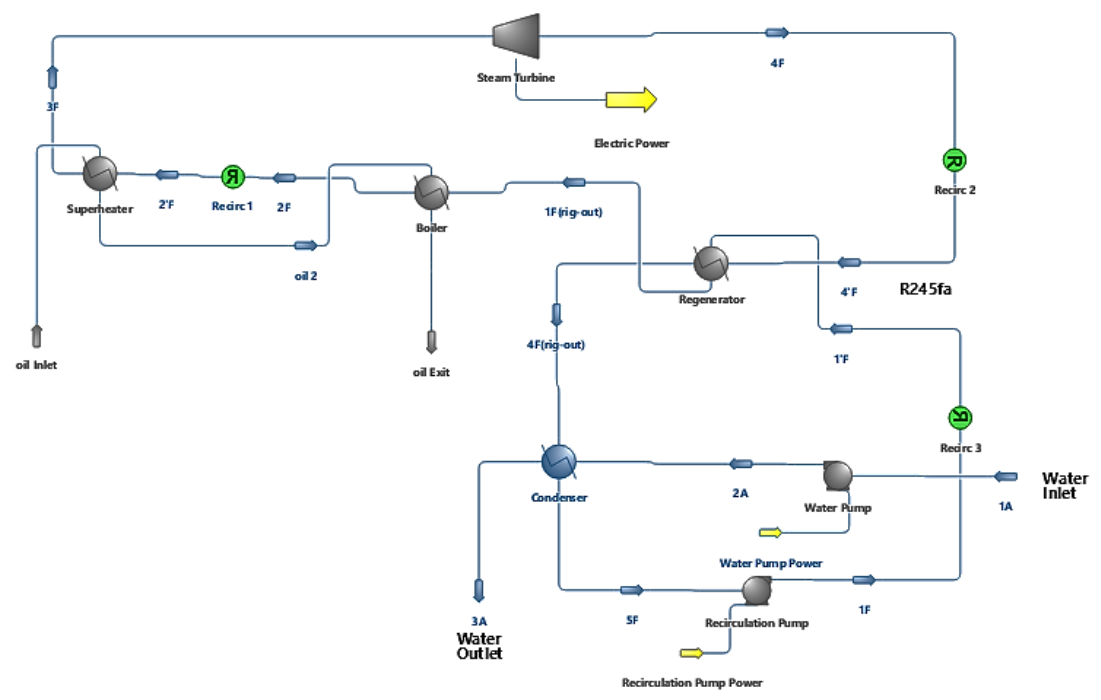

Fig. 2 Schematic view of the Power Block with components. 


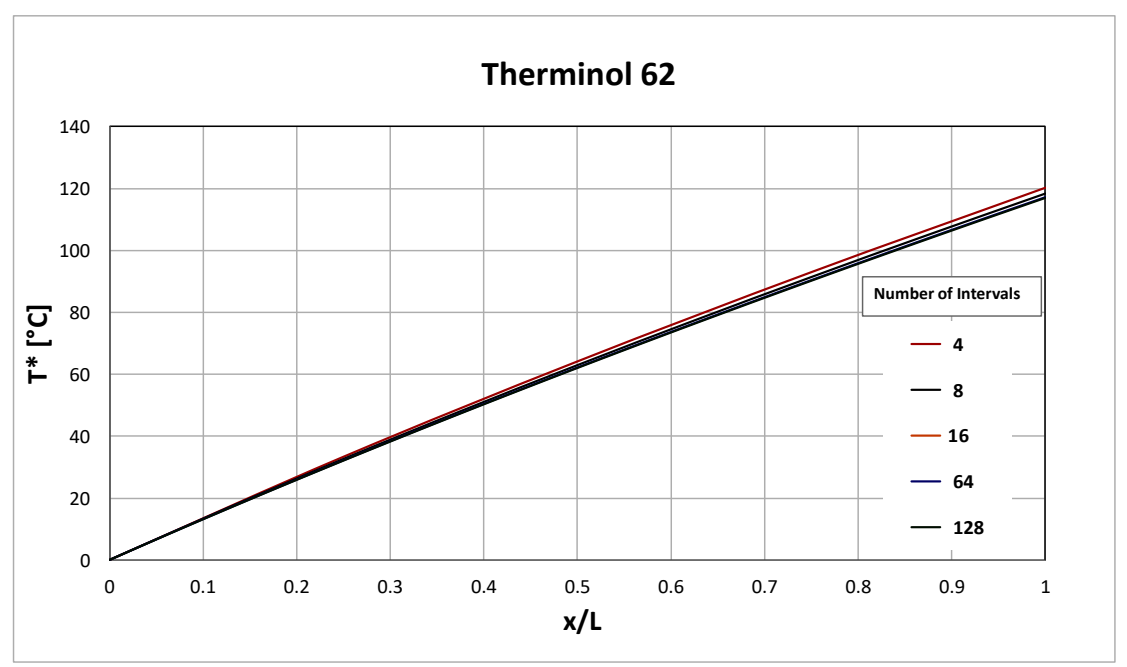

Fig. 3 Temperature distribution along a single HCE string for Therminol 62, different intervals.

The components of the Power Block employed in the simulations are shown in Figure 2. As it can be seen from Figure 2, the plant displays two heat exchangers for the oil and the working fluid thermal interaction: the boiler and the superheater heat exchangers The thermodynamic properties of the working cycle fluids are evaluated considering the fluid entering the steam turbine as dry vapour, i.e. vapour quality equal to 1.0 , or assuming a predefined level of superheating. In any case, a pinch point temperature is assumed between the oil and working fluid temperature values. A regenerative heat exchanger is present in the plant and it can also be switched off when no regeneration effects should be taken into account. Although a superheating heat exchanger is provided in the Power Block, no superheating is used in the current simulations.

\section{DISCUSSION OF RESULTS}

Temperature of the HTF is presented in the next with reference to its inlet value:

$$
T^{*}(x / L)=T(x)-T_{\text {inlet }}
$$

At first, the convergence of the numerical procedure as a function of the total number of elements employed for discretizing the HCE is subdivided is reported in Figure 3. It is observed that the temperature distribution numerical differences with different number of intervals is quite small; thus, a number of 64 elements is employed in the next.

The temperature distribution, referred to the inlet temperature, along the Solar Plant HCE for a single string is reported for Therminol 62 and VP1 oils in Figure 4(a) and (b), respectively.

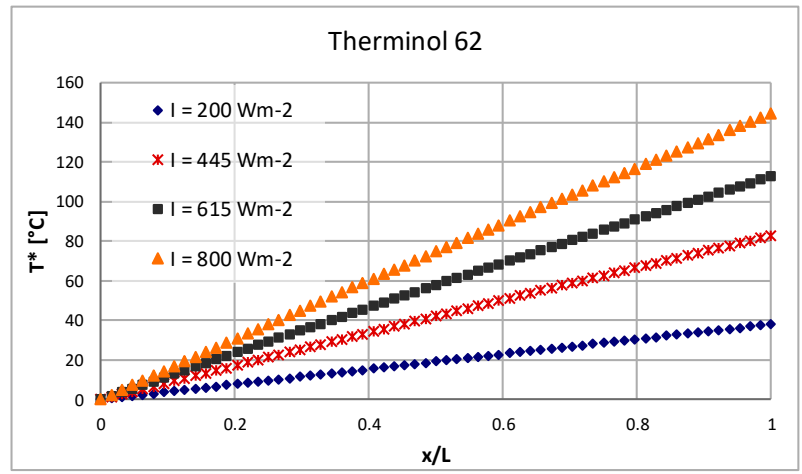

(a)

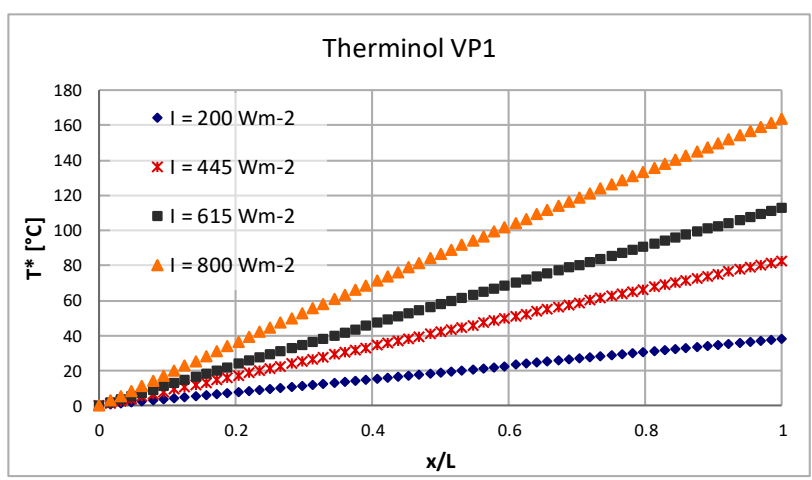

(b)

Fig. 4 Temperature distribution along a single HCE string: (a) Therminol 62; (b) Therminol VP1, with different irradiance values $I=200,445,615$ and $800 \mathrm{Wm}^{-2}$. 


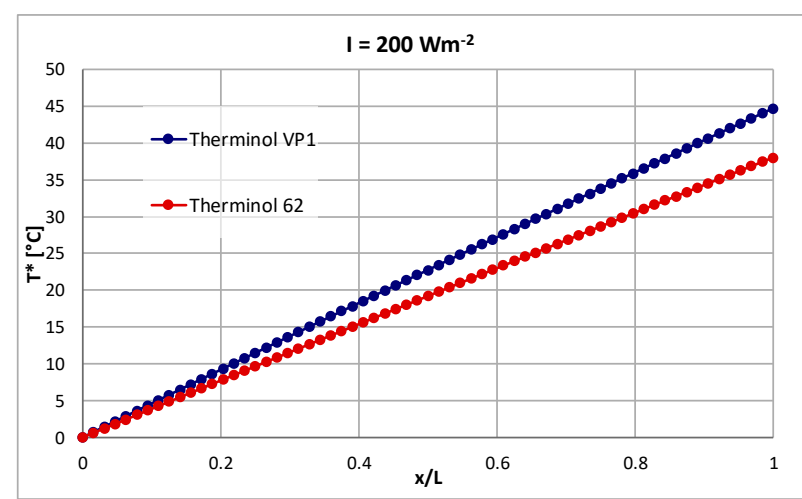

(a)

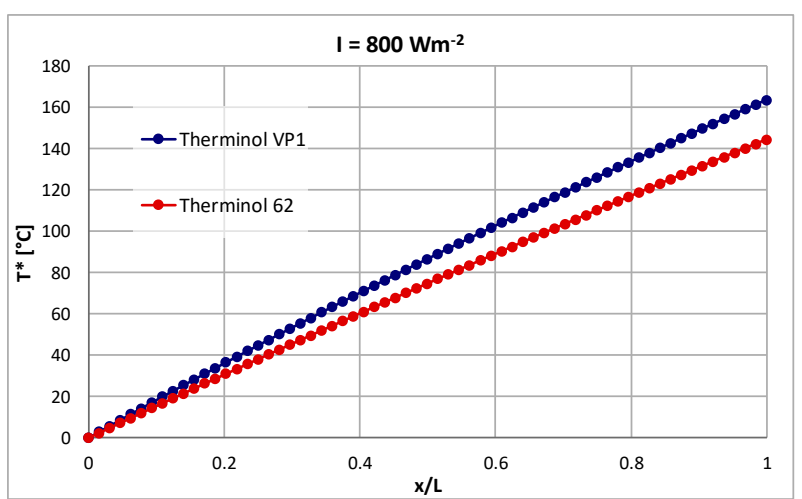

(b)

Fig. 5 Comparison of Therminol VP1 and 62 temperature distribution along a single HCE string. Irradiance $I=$ (a) $200 \mathrm{Wm}^{-2}$, (b) $800 \mathrm{Wm}^{-2}$.

The assumed solar irradiance is equal to $200,445,615$ and $800 \mathrm{~W} / \mathrm{m}^{2}$. The larger the irradiance the greater the temperature increment between inlet and exit of the HCE pipes. For Therminol 62, Fig.4(a) the temperature increment ranges from 20 to around $140{ }^{\circ} \mathrm{C}$ when the irradiance is 200 and $800 \mathrm{Wm}^{-2}$, respectively. The same trend is observed for the Therminol VP1, with larger temperature increments between inlet and exit of the HCE string.

Comparison of the temperature distributions along a single string for the two oils is displayed in Fig.5 for the two extreme values of irradiance, 200 and $800 \mathrm{Wm}^{-2}$, Fig.5(a) and (b) respectively. The assumed mass flow rate flowing in the systems is the same for the two oils. Therminol 62 shows always smaller temperature increments compared with Therminol VP1. The differences at the exit of the circuit, before entering the heat exchanger, are 6 and $20^{\circ} \mathrm{C}$ for the two conditions displayed in Figure 5.

The thermal power that can be transferred to the ORC fluid is reported in Figure 6, for the two oils and different irradiance conditions. For the same mass flow rate flowing in the oil circuit, it is observed that Therminol 62 , Figure 6, provides larger thermal power to transfer to ORC, considering the same irradiance values. The discrepancies range from $17 \%$ to $13 \%$, considering smaller to larger irradiance values. This is an important issue, because the thermal power delivered to the ORC fluid is of outmost importance. Nonetheless, the temperature levels are also essential, since they also force the maximum temperatures that can be attained in the cycle. Thus, these two opposing trends should be carefully evaluated in the choice of the oil.

Oil velocity distributions inside the HCE are reported with the two limit irradiance values, i.e. with $I=200 \mathrm{Wm}^{-2}$ Figure 7(a) and $I=800 \mathrm{Wm}^{-2}$ Figure 7(b). The increment of velocity inside the pipes is due to the decrement of density of the oils, which has been taken into account in the developed numerical model.

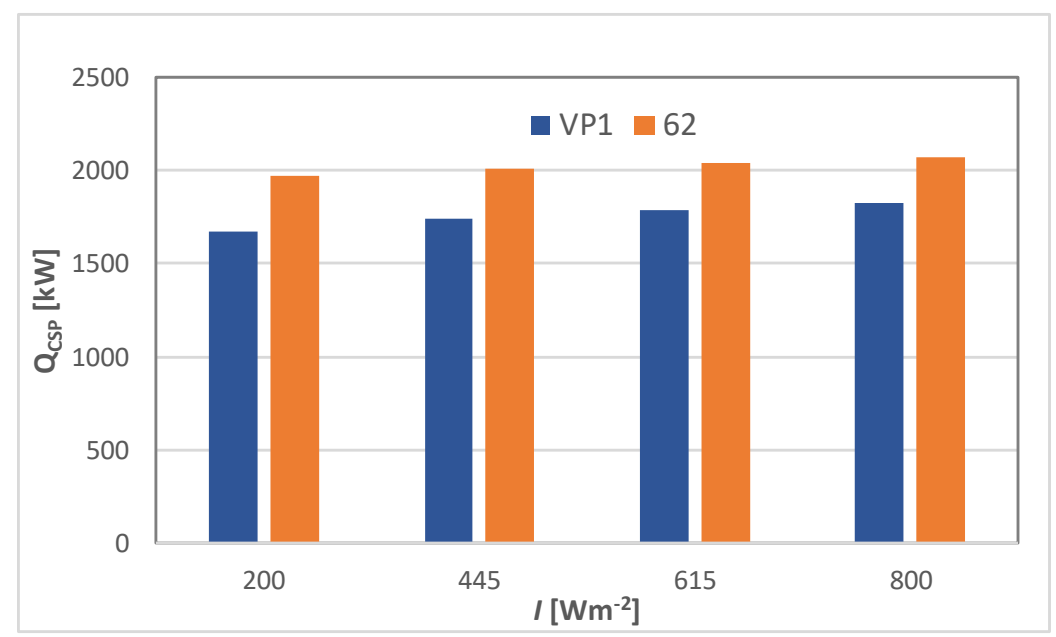

Fig. 6 Comparison of transferred thermal power to the ORC fluids for the two oils and all irradiance values. 


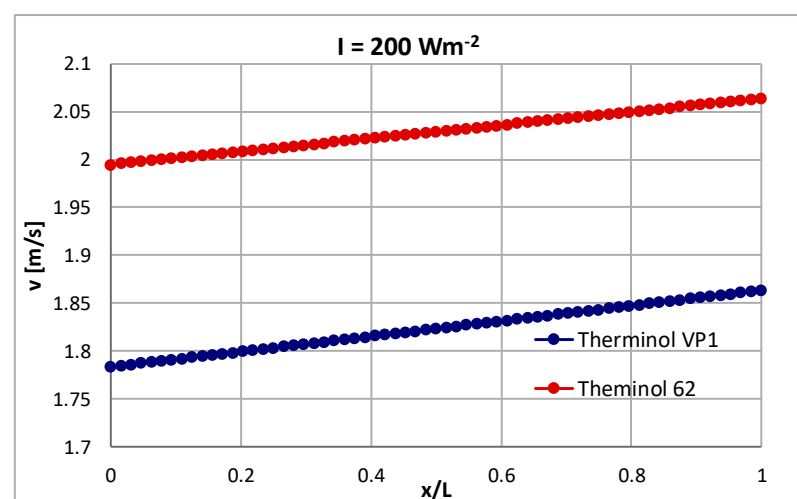

(a)

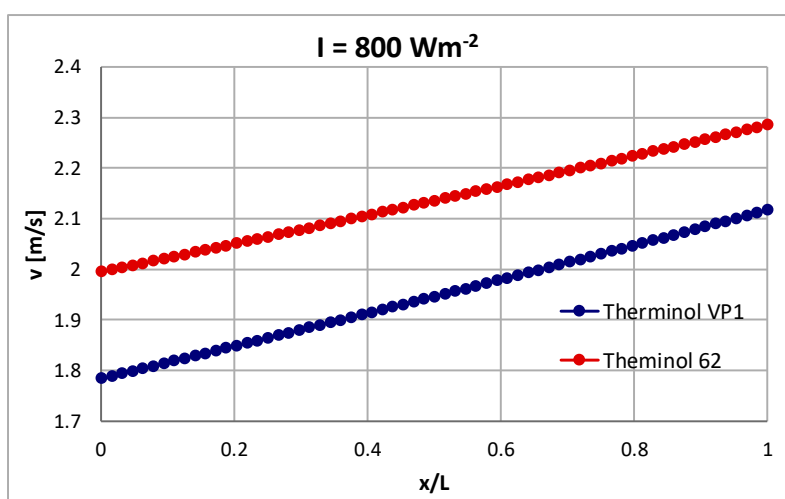

(b)

Fig. 7 Comparison of Velocity distribution along a single HCE string Therminol VP1 and 62 with irradiance $I=$ (a) $200 \mathrm{Wm}^{-2}$, (b) $800 \mathrm{Wm}^{-2}$.

Using the thermal power transferred by the HTF, the main cycle performance values for the three ORC fluids are obtained simulating the cycles using the DWSIM programme. No optimization of the cycle is accomplished in the paper, and main data are reported in Table 3. Maximum pressure of each fluid is obtained considering the thermal interaction of the two fluids in the heat exchanger assuming an heat exchanger efficiency of $90 \%$ and a pinch point equal to around $20^{\circ} \mathrm{C}$.

Without considering superheating, the best cycle efficiency is given by the R245fa with a $14.7 \%$, whereas both R134 and water show lower values. Anyway, the maximum pressure is 20.0 bar for the R245fa and even higher for the R134. Considering the mass flow rates of the working fluids, the lowest value is given by the water with $3.9 \mathrm{~kg} / \mathrm{s}$, whereas R245fa displays a value of around $27 \mathrm{~kg} / \mathrm{s}$ to extract $1 \mathrm{MWe}$ from the plant. Considering different regeneration process percentages, ranging from 0 to $50 \%$, the data for the cycle are different. In fact, as displayed in Table 4, assuming the same ORC mass flow rate, equal to $26.9 \mathrm{~kg} / \mathrm{s}$, there is an increment of the cycle efficiency and a subsequent reduction of the required oil mass flow rate. The cycle efficiency increases up to around $7 \%$, with a oil mass flow rate reduction of around $6 \%$.

Table 3 Main performance values of the ORC for the three investigated working fluids

\begin{tabular}{c|c|c|c}
\hline & $\eta_{\text {ORC }}(\%)$ & $\mathbf{p}_{\text {max }}(\mathbf{b a r})$ & $\dot{m}(\mathbf{k g} / \mathbf{s})$ \\
\hline R245fa & 14.7 & 20.0 & 26.9 \\
R134 & 8.4 & 22.0 & 61.7 \\
Water & 9.5 & 5.0 & 3.9 \\
\hline
\end{tabular}

Table 4 Performance values of the R245fa ORC working fluid with different regeneration levels

\begin{tabular}{c|c|c|c}
\hline $\mathbf{R 2 4 5 f a}$ & $\eta_{\text {ORC }}(\boldsymbol{\%})$ & $\mathbf{p}_{\max }(\mathbf{b a r})$ & $\dot{m}_{\text {oil }}(\mathbf{k g} / \mathbf{s})$ \\
\hline $\mathbf{0 \%}$ & 14.7 & 20.0 & 22.9 \\
$\mathbf{2 0 \%}$ & 15.1 & 20.0 & 22.3 \\
$\mathbf{4 0 \%}$ & 15.5 & 20.0 & 21.8 \\
$\mathbf{5 0 \%}$ & 15.7 & 20.0 & 21.5 \\
\hline
\end{tabular}

\section{CONCLUSIONS}

The coupling of a CSP and ORC is reported in this paper. Analysis of the thermal performance of two oils, Therminol VP1 and 62 is accomplished by a one-dimensional steady analysis. The two investigated oils 
display similar performance both in terms of temperature increment along the HCE and velocity. Anyway, the thermal power delivered to the ORC fluid is slightly different for the two oils, with Therminol 62 showing larger values for the same irradiance considered. Nonetheless, the temperature levels are also fundamental, since they impose the maximum temperatures and pressure that can be attained in the cycle. With this regard, Therminol VP1 shows the larger temperature increment, allowing ORC fluid to attain higher temperature values. Thus, these two opposing trends should be carefully evaluated in the choice of the HTF oil.

The power block is simulated with three different working fluids: R245fa, R134 and water. The R245fa is the best working fluid in terms of cycle efficiency, instead considering the mass flow rate water displays the lowest value. Also, data for a regenerative cycle are shown which highlight the cycle efficiency increments and oil mass flow rate reduction.

\section{ACKNOWLEDGMENT}

V:ALERE 2019 grant support from Università degli studi della Campania "L. Vanvitelli" of CHIMERA project is gratefully acknowledged.

\section{NOMENCLATURE}

\begin{tabular}{|c|c|c|c|c|c|}
\hline$A$ & cross section of the HCE & $\left(\mathrm{m}^{2}\right)$ & $\Delta x$ & Interval length & (m) \\
\hline$A_{c}$ & cross section of the pipe & $\left(m^{2}\right)$ & $\eta_{\mathrm{opt}}$ & optical efficiency & $(-)$ \\
\hline$c$ & specific heat & $(\mathrm{kJ} / \mathrm{kg} \mathrm{K})$ & $\eta_{\mathrm{ORC}}$ & ORC efficiency & $(-)$ \\
\hline$D$ & diameter & (m) & & density & $\left(\mathrm{kg} / \mathrm{m}^{3}\right)$ \\
\hline$\dot{m}$ & mass flow rate & $(\mathrm{kg} / \mathrm{s})$ & & & \\
\hline$I$ & Irradiance & $\left(\mathrm{Wm}^{-2}\right)$ & \multirow{11}{*}{$\begin{array}{l}\text { SUBS } \\
\text { cond } \\
\text { conv } \\
\text { ext } \\
\text { i } \\
\text { inc } \\
\text { irr } \\
\text { NET } \\
\text { oil }\end{array}$} & RIPTS & \\
\hline$L$ & Length of the HCE string & (m) & & conduction & \\
\hline$L_{m i r}$ & Length of the mirror & (m) & & convection & \\
\hline$P$ & wetted perimeter of the pipe & (m) & & external & \\
\hline$p$ & pressure & (bar) & & axial location & \\
\hline$q$ & heat flux & $\left(\mathrm{Wm}^{-2}\right)$ & & incident & \\
\hline$Q$ & Thermal power & $(\mathrm{W})$ & & irradiation & \\
\hline$T$ & Temperature & $(\mathrm{K})$ & & net power & \\
\hline$T^{*}$ & \multicolumn{2}{|c|}{ Temperature referred to inlet value $(\mathrm{K})$} & & oil & \\
\hline$x$ & axial coordinate & $(-)$ & & & \\
\hline$v$ & velocity & $\left(\mathrm{m}^{2} / \mathrm{s}\right)$ & & & \\
\hline
\end{tabular}

\section{REFERENCES}

[1] Bellos, E., Tzivanidis, C., and Antonopoulos, K.A.,"A detailed working fluid investigation for solar parabolic trough collectors," Applied Thermal Engineering, 114, pp. 374-386, (2017).

[2] Xu, X., et al.,"Prospects and problems of concentrating solar power technologies for power generation in the desert regions," Renewable and Sustainable Energy Reviews, 53, pp. 1106-1131, (2016).

[3] Mansour, K., Boudries, R., and Dizene, R.,"Optical, 2D thermal modeling and exergy analysis applied for performance prediction of a solar PTC," Solar Energy, 174, pp. 1169-1184, (2018).

[4] Salgado Conrado, L., Rodriguez-Pulido, A., and Calderón, G.,"Thermal performance of parabolic trough solar collectors," Renewable and Sustainable Energy Reviews, 67, pp. 1345-1359, (2017).

[5] Padilla, R.V., et al.,"Heat transfer analysis of parabolic trough solar receiver," Applied Energy, 88(12), pp. 5097-5110, (2011).

[6] Padilla, R.V., et al.,"Exergy analysis of parabolic trough solar receiver," Applied Thermal Engineering, 67(1), pp. 579-586, (2014).

[7] Kalogirou, S.A.,"A detailed thermal model of a parabolic trough collector receiver," Energy, 48(1), pp. 298-306, (2012).

[8] Forristall, R., Heat Transfer Analysis and Modeling of a Parabolic Trough Solar Receiver Implemented in Engineering Equation Solver. NREL: Colorado, United States, (2003)

[9] Eastman Co., Ultrahigh-temperature, vapor/liquid phase fluid $-12^{\circ} \mathrm{C}$ to $400^{\circ} \mathrm{C}$. Eastman Kingsport, USA. p. 8, (2016).

[10] Duffie, J., A., and Beckman, W., A., Solar Engineering of Thermal Processes. 4th ed. United States: J. Wiley \& Sons.pp. 928 , (2013).

[11] European Joint Research Center, PVGIS Project. European Commission, (2019). 